\title{
Short GC-rich RNA similar to miR 1909 and 1915 folds in silico with the 5'-UTR and ORF of Notch and responders: Potential for the elimination of cancer stem cells
}

\author{
YUFENG LI ${ }^{1}$, TAKASHI MINE ${ }^{1}$ and CONSTANTIN G. IOANNIDES ${ }^{2}$ \\ Departments of ${ }^{1}$ Melanoma Medical Oncology, and ${ }^{2}$ Experimental Therapeutics, The University of Texas \\ MD Anderson Cancer Center, 1515 Holcombe Blvd., Houston, TX 77030, USA
}

Received May 19, 2010; Accepted August 20, 2010

DOI: 10.3892/or_00001004

\begin{abstract}
Novel therapeutic approaches to eliminate cancer stem cells (CSCs) are being developed. This development is imperative as CSCs are resistant to drugs; they divide activated by ligands on the epithelium or on neighboring cancer cells. Specific commands for division originate from Notch-1 ligands. Notch-1 cleavage inhibitors can have opposite effects from the ones expected when the levels of Notch ligands are high on neighboring cancer cells. High levels of Jagged-1 are a common feature of ovarian tumors. Some gene pathways enhance, others repress transcription of
\end{abstract}

Correspondence to: Dr Constantin G. Ioannides, Department of Experimental Therapeutics, MD Anderson Cancer Center, Box 304, Houston, Texas 77030, USA

E-mail: cioannid@mdanderson.org

E-mail: constantinioannides@gmail.com

Special abbreviations: eRNA, effector-RNA, short RNA which mediates biological effects; nt, nucleotide, target site, complementary nt sequence (A->T, C->G) of miR or anti-HHB in mRNA; $\Delta \mathrm{G}$, free energy of hybridization/folding of short RNA with its target site (in $\mathrm{Kcal} / \mathrm{mol}$ ); \{\} , accolades indicate hybrid/fold partners. Target (s), target sites, i.e. RNA sequences which can have Watson-Crick complementary nucleotide sequences to miRs and artificial short RNAs; folding, folding or hybridization of two nucleotide strands as described by M-fold server; HHBN1, high hydrogen bond, 24-nt long, GC-rich-RNA from Notch-1, anti-HHB, complementary short RNA to Notch-1 mRNA(33-56); Self- $\Delta \mathrm{G}$, free energy of self-folding of RNA; Net- $\Delta \mathrm{G}$, impact: mean Net- $\Delta \mathrm{G}$ per bond; Kcal, Kcal/mol

Common abbreviations: 5' and 3'-UTRs, 5' and 3'-untranslated regions; ORF, open-reading frame; EIF4s (-E1, -A and -G), elongation initiation factors; HIF- $1 \alpha$, hypoxia-induced factor; hESCs, human embryonal stem cells; c-Myc, c-Myc oncogene; CSCs, cancer stem cells; EMT, epithelial to mesothelial transition; ESCs, embryonal stem cells; SCFs, stem cell factors: Slug, Snail, Ronin, Sox-2, Nanog, Oct-3/4

Key words: mRNA, GC-rich RNA, translation inhibition, RNA loops, cancer, transposon
Notch-1, while Notch-1 itself activates Myc and HIF-1 $\alpha$. RNA-based therapies need effector RNAs (eRNAs) with broad and focused specificity. eRNAs are short RNAs (20-30 nt long) which mediate biological effects. Two to three inhibitory RNAs with high net folding/hybridization/binding (and thereafter folding), and free energy (Net- $\Delta \mathrm{G}$ ) with multiple mRNAs can replace many miRs as eRNAs and overcome the complexity of identification of specific targets for each miR and competitive inhibition on delivery of small amounts of many miRs at the same time. To discover candidate eRNAs with multiple high affinity target sites or sequences (and thereafter targets), we searched for sequences containing more than randomly probable $\mathrm{G}$ and $\mathrm{C}$. $\mathrm{G}$ and $\mathrm{C}$ bind with more hydrogen bonds than the pair A:T. We identified the sequence, Notch-1,33-56 in the ORF of Notch-1 mRNA. Notch-1,33-56 has a GC frame of 2 asymmetrical halves in 24 nucleotides. Each GC group has a different third nucleotide. Since GC is repeated, the third nucleotide defines the specificity as a 'bar code'. The complementary strand to Notch-1,33-56, binds in silico nt at 5'-UTR, ORF and 3'-UTR of mRNA. For simplification, the sequence of Notch-1,33-56 was designated HHN1 and its complementary strand, antiHHB. We introduced novel quantitative parameters: Net- $\Delta \mathrm{G}$ and mean Net- $\Delta \mathrm{G} /$ bond. We quantified the Net- $\Delta \mathrm{G}$ of folding, in silico, of anti-HHB with additional targets in Notch-1,1404. The targets of anti-HHB contained 11-12 complementary nucleotides and formed small loops with anti-HHB upon folding. Anti-HHB folded with 3-4 distinct targets in each mRNA from 50 mRNAs. Targets were in 5'-UTR (40\%), ORF (50\%) and 3'-UTR (10\%). Anti-HHB also folded with high Net- $\Delta \mathrm{G}$ with Notch-1 targets, c-Myc and HIF-1 $\alpha$, suggesting it can inhibit EMT. Human embryonal stem cell (hESC) miRs, 1909 and 1915, folded with Notch-1,8-29 and Notch$1,33-56$, respectively with a similar Net- $\Delta \mathrm{G}$ as anti-HHB. This finding suggested a natural feedback mechanism aiming to inhibit Notch-1 translation which is activated in stem cells by miRs with a similar sequence as anti-HHB, and anti-HHB can be used when the miRs 1915 and 1909 are absent. The consensus sequence of 18 targets folded with HHB with the highest Net- $\Delta \mathrm{G}$ (range -10.20 to $24.00 \mathrm{Kcal} / \mathrm{mol}$ ) similar to that of two Drosophila transposons. Targeting 'domesticated transposons' carried by humans with eRNAs may become a universal approach to treat cancer. Anti-HHB is the first 
candidate eRNA to fold, in silico, with multiple targets in 5'-UTR and ORF of Notch-1 partners with at least 2-times higher $\Delta \mathrm{G}$ than natural miRs with 3'-UTR Notch-1.

\section{Introduction}

One novel approach to the treatment of cancer is the identification of specific targets in the mRNA of cancer genes for short RNAs (sRNAs). sRNAs can inhibit mRNA translation and sometimes gene transcription. We aimed to identify sRNAs with the highest binding affinity for target sites on mRNAs. In 2009, databases listed more than 2000 human miRs. Potential targets of miRs are defined by their 'seed-matches' with their targets. 'Match' means partial Watson-Crick type complementarities between the nucleotides (nt) of miR and its target. The $3^{\prime}$ of the target in the 3'-UTR of mRNA is complementary to the 5'-miR sequence. The target must be at least 7 nucleotides long; the 'seedmatch' on the miR $5^{\prime}$ end is completed by several matches between the miR $3^{\prime}$ end and the target. When there are no matches at intermediate positions between nt 7 and 13, miRs fold with large loops with the targets. Such structures are unstable.

The number of matches of miRs with the target and folding energy are not compared to quantify significance. G and C contribute more to folding energy than $\mathrm{A}$ and $\mathrm{T}$. Each miR has hundreds of targets, exceeding any reasonable expectation of specificity (1). There are no methods to predict the preference and effects of miRs on targets. Each target must be experimentally confirmed. Distinction between enhancement and inhibition of translation cannot be predicted (2). Furthermore, $\mathrm{miR}$ and $\mathrm{miR}-\mathrm{Star} / \mathrm{miR}^{*}$ (miR complementary strand in premiRNA) fold with additional targets in the 5'-UTR and ORF of Notch-1 mRNA (miR-802; Li and Ioannides, unpublished data) (3-5).

The classical model of translation-start in healthy cells asserts that mRNA is synthesized in the nucleus and is then transferred to the cytoplasm where it folds head to tail and rests in RNA stores until needed. Since stem cells divide symmetrically, recent findings suggest that these RNA stores are exhausted rapidly, within $24 \mathrm{~h}$ in metastases. mRNA transcription and translation to proteins are an in-line process which skips the folding of 3'-UTR with 5'-UTR and the accumulation of stored RNA (6). Inhibition of reading by the ribosome of 5'-UTR and ORF of mRNA becomes priority to inhibit the synthesis of cancer-effector proteins.

Inhibitory 'butterfly' RNAs, created by us to target 3'UTR of HER-2 and Gli-1, inhibited the proliferation of cancer cells by $40-50 \%$ within $72 \mathrm{~h}(7,8)$. Surviving cells recovered and proliferated faster. 'Butterfly Gli-1-RNA' exhibited two effects: i) non-specific; deletion of a large number of cells; this effect was equal in magnitude with the effect of negative control siRNA and ii) specific; inhibition of the division of small cells; small cells are considered 'quiescent CSCs' (8). The inhibitory effect was stronger in cells which divided 3 and 4 times $(9,10)$. A different type of effector RNA (eRNA) which interferes with the initiation of division of CSCs is therefore needed.

Notch-1 and its ligands (Delta and Jagged) control an ancestral pathway of cell division and organ formation which is conserved in humans (11). Notch-1 controls cell cycle progression from G0 to G1. The Notch-1 pathway is important as it precedes activation by oncogenes. Notch-1 activates $c-m y c$ and hypoxia genes, which in turn activate expression of ESC genes (12). Notch-1 synergizes or antagonizes HER-2, depending on the environment. Notch-1 controls hypoxia by representing the HIF- $1 \alpha$ and several HIF-1 $\alpha$-associated stem cell factors (SCFs) $(13,14)$.

Notch activation starts from a signal from Delta and Jagged on the neighboring cell. The signal 'pulls and breaks' the Notch heterodimer. The Notch-1 extracellular domain, N1ECD, is endocytosed together with Delta/Jagged in neighboring cells. The intracellular domain of Notch-1 protein (N1ICD) binds its suppressor, Numb, and pushes it for degradation. Signals from Notch-1 co-activator family, Mastermind-like-1 members, enhance Notch-1 signaling.

Independently, Sonic Hedgehog ligands activate the signal transducer, Gli-1, which in turn amplifies Notch-1 signals and activates Bim. Numb, as it is degraded cannot protect p53 (TP53); thus, cancer cells progress to phase $\mathrm{S}$ and G2M. Cell division is activated by the N1ICD effector by at least two pathways: i) direct to nuclear factor $\mathrm{RBjK}$ and ii) indirect to c-Myc $(15,16)$. c-Myc induces de-differentiation (EMT), defined as re-expression of embryonal genes.

We hypothesized that: i) translation of Notch-1 and its targets can be inhibited at initiation (5'UTR and ORF) and ii) the optimal candidate Notch-1-inhibitor must bind to and inhibit expression of c-Myc, HIF-1 $\alpha$, Ras and at least one SCF. Optimal inhibitors of Notch-1 translation must not completely relieve suppression of Notch-1 translation. In other words, the less the inhibitor folds with suppressors of Notch-1 the better the outcome.

The sequence Notch-1,33-56, (HHN1) is in the 5'-start of ORF of Notch-1. We folded its complementary sequence, anti-HHN, in silico, with 50 distinct mRNAs. To measure specificity of the quantification of energy of folding of antiHHB and compare these values with all reported miRs which target Notch-1 mRNA, we quantified the specific Net- $\Delta \mathrm{G}$ of folding. Net- $\Delta \mathrm{G}$ is masked when ' $\Delta \mathrm{G}$ ' is quantified. We further quantified the average/mean: mean (Net- $\Delta \mathrm{G}) /$ bond of folding of anti-HHB with the target by dividing the Sum $(\Sigma)$ of Net- $\Delta \mathrm{G}$ on several targets and intervening non-folding $n t$. The effects of anti-HHB (and of miRs) are stronger when high $\Delta \mathrm{G}$ is applied on a long sequence than when low $\Delta \mathrm{G}$ is applied on a short sequence.

Anti-HHB folded with targets in mRNAs encoding proteins associated with Notch-1 function with $>2$ times higher Net- $\Delta \mathrm{G}$ than the average Net- $\Delta \mathrm{G}$ of natural miRs for Notch-1. Anti-HHB folded only with 10 unrelated targets of $>35,000$ in RefSeq, with a similar Net- $\Delta \mathrm{G}$ as for Notch-1 mRNA (Table I).

Anti-HHB folded at least 3-4 targets in each mRNA with similar affinity. The folded sequences are in ORF (50\%) and 5 '-UTR $(40 \%)$. The targets of anti-HHB folded with high Net- $\Delta \mathrm{G}$ were present in Notch-1, Notch-2, EGF-R, c-myc, Ras, HIF- $1 \alpha$ and its associated SCF, Slug $(17,18)$. Anti-HHB has similar targets with newly identified natural miRs in hESCs (19) suggesting that a similar RNA sequence controls CSC division and is absent in metastatic cancer cells. 
Table I. Sequences unrelated to Notch-1 and its partners folded with anti-HHB with a high Net- $\Delta \mathrm{G}$.

\begin{tabular}{|c|c|c|c|c|c|c|c|}
\hline & RefSeqNM_ & Name & Region & Target & Matches & $\Delta \mathrm{G}$ & Net- $\Delta \mathrm{G}$ \\
\hline 1 & 001047.2 & Steroid- $\alpha$-reductase- $\alpha$-polypeptide & ORF & $221-$ & $17 / 18$ & 23.80 & 12.60 \\
\hline 2 & 080605.3 & UDP-Gal:ß-Gal-ß-polypeptide 6 & ORF & 386-, & $15 / 15$ & 29.90 & 17.60 \\
\hline 3 & 002958.3 & RYK-receptor-kinase-like motif & ORF & 196-, & $15 / 15$ & 26.20 & 14.70 \\
\hline 4 & 001020.4 & Ribosomal protein & ORF & $481-$ & $19 / 21$ & 26.70 & 15.60 \\
\hline 5 & 006690.3 & Matrix metallopeptidase & ORF & 113-, & $16 / 16$ & 25.90 & 15.40 \\
\hline 6 & 139072.3 & $\Delta$ Notch-like EGF-motif & ORF & $181-$ & $18 / 19$ & 24.80 & 11.70 \\
\hline 7 & 001141972.1 & ATP-binding domain 4, ATPBD4 & 5'UTR & $18-$ & $19 / 21$ & 28.00 & 15.70 \\
\hline 8 & 005929.4 & P97-melanoma & ORF & 2283-, & $20 / 21$ & 20.80 & 11.90 \\
\hline 9 & 017802.3 & HEAT-repeat containing 2 & ORF & $367-$ & $20 / 20$ & 25.30 & 13.60 \\
\hline- & 017617.3 & Notch-1 & ORF & 33-, & $24 / 24$ & 27.60 & 13.40 \\
\hline
\end{tabular}

CDRs are: 1, 191-970; 2, 31-1020; 3, 91-1914; 4, 84-524; 5, 4.4-1941; 6, 148-2361; 7, 63-560; 8, 114-2330; 9, 21-2558; Notch-1, 1-7609.

\section{Materials and methods}

The methodology for such studies as the present one is not organized. Sequences were extracted from the NCBI database. Nucleotide homologies were identified with BlastN (www.ncbi.nlm.nih.gov/blast/Blast). Sequence alignments were made with the Clustal-W2 program (ebi.ac.uk/ Tools/clustalw2/index.html). Positions of promoter binding by anti-HHB were identified with Promo-2 (http://www.cbs. dtu.dk/services/Promoter/) and TRANSFAC (http://transfac. gbf.de). miR translation was performed with EMBOSS suite package (http://biocluster.hgen.slu.se/emboss/). The consensus sequence of 18 targets of anti-HHB was identified with Jalview (www.jalview.org).

Position and Self- $\Delta \mathrm{G}$ of self loops formed by 5 '-UTR and ORF were identified with Genebee Server, 2001 (www. genebee.msu.su). Folding of miRs and anti-HHB with sequences of equal length was performed on Bibiserv (http://bibiserv.techfa.uni-bielefeld.de) and verified with the M-fold server (www.bioinfo.rpi.edu/zukerm/rna) (20-23). Hybridization energies and structures were quantified with M-Fold server for uniformity. We present all Net- $\Delta \mathrm{G}$ values. Net- $\Delta \mathrm{G}$ reported by the servers varied. For example, $\Delta \mathrm{G}$ of HHN1 folded with anti-HHB is $-26 \mathrm{Kcal}$ by M-fold and -37 Kcal by Bibiserv. Another server (unlisted in that paper) indicates $-21.6 \mathrm{Kcal}$ for the hybrid \{miR-10:Rsp-2\} (5). M-fold indicates, for the same hybrid, a $\Delta \mathrm{G}$ of $-13.6 \mathrm{Kcal}$ and a Net$\Delta \mathrm{G}$ of $-6.40 \mathrm{Kcal}$. According to M-fold, the hybrid \{miR7a:Rsp-2\} has a $\Delta \mathrm{G}$ of $-6.40 \mathrm{Kcal}$ and a Net-G of $-4.80 \mathrm{Kcal}$. Although its Net- $\Delta \mathrm{G}$ was not reported, miR-7a affected expression of EGF-R (24) suggesting that it is reasonable to expect an effect at a Net- $\Delta \mathrm{G}$ of $-5.00 \mathrm{Kcal}$.

To select high affinity targets, we ignored sequences $<50 \%(12 / 24)$ complementary to anti-HHB. To eliminate target overlap, we replaced with poly-A, in mRNAs, each target identified before we searched for the next target. We selected for in silico folding sequences partially homologous to HHN1 with an alignment score $>50$. We quantified the $\Delta \mathrm{G}$ of anti-HHB for all targets. We permitted only 3-nt gaps in partially homologous sequences of HHBN1 and only 3-4 unmatched consecutive nucleotides unfolded between partners (no loops larger than $6 \mathrm{nt}$ ). Our approach reduced the probability to 'discover' RNA sliceable in the middle due to the large loops formed.

To distinguish the net folding energy of anti-HHB with each target we introduced the Net- $\Delta \mathrm{G}$. M-fold and Bibiserv report only total $\Delta \mathrm{G}$. M-fold and Bibiserv do not consider the target as part of the stem/self loop. Each 24 nt-long RNA single strand tends to self-fold in the most energetically stable state. Each RNA has its own energy of self-folding. The unbound state of anti-HHB and its folding RNA partner was designated here as Self- $\Delta \mathrm{G}$. In silico folding may show artificially high $\Delta \mathrm{G}$. Artificially high $\Delta \mathrm{G}$ is the sum of individual Self- $\Delta \mathrm{Gs}$ of the anti-HHB and its target. Net- $\Delta \mathrm{G}$ is the balance after subtracting from $\Delta \mathrm{G}$ the Self- $\Delta \mathrm{G}$ according to the formula:

Net- $\Delta \mathrm{G}$ [Folded $\{$ anti-HHB:Target $\}]=\Delta \mathrm{G}$ [folded partners] - Self- $\Delta \mathrm{G}$ [anti-HHB] - Self- $\Delta \mathrm{G}$ [Target].

We identified the targets in the stem loops and the energy (in Kcal) holding the loops stable. To change the mRNA structure, free (negative)- $\Delta \mathrm{G}$ of folding \{anti-HHB:target\} should be higher than the Net- $\Delta \mathrm{G}$ of the loop/self-loop containing the target.

Assume that Self- $\Delta \mathrm{G}$ of anti-HHB is $-7.50 \mathrm{Kcal}$; Self- $\Delta \mathrm{G}$ of the stem-loop containing the target is $-10.0 \mathrm{Kcal} ; \Delta \mathrm{G}$ of the resulting folded anti-HHB:target\} is $-15.00 \mathrm{Kcal}$. This value means the stem-loop containing the target is closed, and anti-HHB may bind but does not fold. Calculated Net$\Delta \mathrm{G}$ from the values above indicated no folding: [-15.00 $(-7.50-10.00)=+2.50 \mathrm{Kcal}]$.

Anti-HHB folds with its target when i) the structure of the loop changes, and ii) $\Delta \mathrm{G}$ of folding is greater than $\Sigma$ (individual $\Delta \mathrm{G}$ ) by at least $-5.00 \mathrm{Kcal}$. In the example, $\Delta \mathrm{G}$ of the hybrid should be $-20.0 \mathrm{Kcal}$ to predict a low effect. $\{-20.00-[-7.50-10.0]=-2.50 \mathrm{Kcal}\}$. To reach Net $\Delta \mathrm{G}$ of $-5.00 \mathrm{Kcal}$, the $\Delta \mathrm{G}$ of the hybrid must be $-22.50 \mathrm{Kcal}$. A significant effect should be observed at fold $\Delta \mathrm{G}$ of $-7.50 \mathrm{Kcal}$. Genebee lists an average Self- $\Delta \mathrm{G}$ of $-5 \mathrm{Kcal}$ for self-loops composed of 10-12 nt, and approximately 11-13 Kcal for the 
Table II. Anti-HHN targets in the stem cell factors.

\begin{tabular}{|c|c|c|c|c|c|}
\hline Name & Sequence & Domain & Net- $\Delta \mathrm{G}$ & Net- $\Delta \mathrm{G} \mathrm{cal} /$ bond & Predicted effect \\
\hline Notch-1(1-7668) & 15-, 33-, 61-, 377- & ORF & $\begin{array}{c}9.20,13.50 \\
9.50,13.60,8.70\end{array}$ & $\begin{array}{l}475.00 \\
136.25\end{array}$ & $\begin{array}{c}\text { High } \\
\text { Medium }\end{array}$ \\
\hline \multicolumn{6}{|l|}{ Stem cell factors } \\
\hline Oct 3,4 & $\begin{array}{l}\text { A.60-, } \\
\text { A.227-, } \\
\text { B.1085-, }\end{array}$ & $\begin{array}{l}\text { ORF } \\
\text { ORF' } \\
\text { ORF }\end{array}$ & $\begin{array}{r}9.30 \\
6.60 \\
13.80\end{array}$ & 83.24 & Low \\
\hline Nanog & $\begin{array}{l}\text { A.33-, } \\
\text { B.1442-, } \\
\text { B.1492- }\end{array}$ & $\begin{array}{l}\text { 5'UTR } \\
\text { 3'UTR } \\
\text { 3'UTR }\end{array}$ & $\begin{array}{l}9.30 \\
8.90 \\
7.00\end{array}$ & $\begin{array}{r}220.83 \\
17.01\end{array}$ & High \\
\hline Sox-2 & $\begin{array}{c}288-311 \\
449-472 \\
1265-1288\end{array}$ & $\begin{array}{l}\text { 5'UTR } \\
\text { ORF } \\
\text { ORF }\end{array}$ & $\begin{array}{r}7.80 \\
14.00 \\
8.30\end{array}$ & $\begin{array}{r}120.54 \\
30.07\end{array}$ & Medium \\
\hline Ronin & $\begin{array}{c}47-70 \\
534-557 \\
845-868\end{array}$ & $\begin{array}{l}\text { 5'UTR } \\
\text { ORF } \\
\text { ORF }\end{array}$ & $\begin{array}{r}7.50 \\
6.00 \\
11.40\end{array}$ & $\begin{array}{l}51.94 \\
30.29\end{array}$ & $\begin{array}{l}\text { None } \\
\text { None }\end{array}$ \\
\hline $\mathrm{HIF}-\alpha$ & $\begin{array}{c}8-23 \\
30-53 \\
224-246\end{array}$ & $\begin{array}{l}\text { 5'UTR } \\
\text { 5'UTR } \\
\text { 5'UTR }\end{array}$ & $\begin{array}{r}10.80 \\
10.80 \\
8.40\end{array}$ & $\begin{array}{l}450.00 \\
125.00\end{array}$ & $\begin{array}{l}\text { High } \\
\text { Medium }\end{array}$ \\
\hline Slug & $\begin{array}{c}30-53 \\
62-85 \\
121-144\end{array}$ & $\begin{array}{l}\text { 5'UTR } \\
\text { 5'UTR } \\
\text { 5'UTR }\end{array}$ & $\begin{array}{r}12.20 \\
7.60 \\
15.00\end{array}$ & $\begin{array}{l}305.26 \\
360.00\end{array}$ & High \\
\hline Snail & $\begin{array}{c}29-52 \\
228-251 \\
371-393\end{array}$ & $\begin{array}{l}\text { 5'UTR } \\
\text { ORF } \\
\text { ORF }\end{array}$ & $\begin{array}{l}8.00 \\
8.40 \\
7.80\end{array}$ & $\begin{array}{l}64.94 \\
98.79\end{array}$ & $\begin{array}{l}\text { Low } \\
\text { Low }\end{array}$ \\
\hline Twist & $\begin{array}{l}179-202 \\
717-740 \\
973-996\end{array}$ & $\begin{array}{l}\text { 5'UTR } \\
\text { ORF } \\
\text { 3'UTR }\end{array}$ & $\begin{array}{r}14.10 \\
12.70 \\
9.00\end{array}$ & 35.94 & Low \\
\hline
\end{tabular}

CDRs: Twist (392-960), Snail (71-865), Slug (165-971), HIF- $\alpha$ (405-2885), Ronin (246-1190), Sox-2 (428-1381), Nanog (217-1134), Oct-3,4 (55-1137).

most stable loops of $20 \mathrm{nt}$. To normalize Net- $\Delta \mathrm{G}$ for variable lengths, we introduced an indicator of impact of folding of anti-HHB with several targets in the same mRNA:

Mean Net- $\Delta \mathrm{G} /$ bond $=\Sigma\left\{\right.$ Net- $\Delta \mathrm{G}_{1}+$ Net $-\Delta \mathrm{G}_{2}+$ Net $\left.-\Delta \mathrm{G}_{3}+\right\}$ divided by the number of bonds.

Net- $\Delta \mathrm{G}$ was determined as above; $\Sigma\left\{\right.$ Net- $\left.\Delta \mathrm{G}_{1,2,3}\right\}$ the sum of Net- $\Delta \mathrm{G}$ closest to each other on a non-overlapping sequence. The number of bonds is the number of $n t$ in 2-4 closest targets plus the nt between the targets. To distinguish the potential affect by anti-HHB, we separated the mean Net$\Delta \mathrm{G} /$ bond into categories of high (200-500 cal), medium (100$180 \mathrm{cal})$ and low (<100 cal) (Table II-IV). Assume that 23 bonds exist between $24 \mathrm{nt}$, then the total high mean Net$\Delta \mathrm{G} /$ bond ranges between -4.60 and $11.50 \mathrm{Kcal}$, while the low mean Net- $\Delta \mathrm{G} /$ bond is $-2.3 \mathrm{Kcal}$. A value of $-5.00 \mathrm{Kcal}$ per $12 \mathrm{nt}$ equals $416 \mathrm{cal}$ per bond; this means 1 of $2 \mathrm{nt}$ in the 24mer forms a H-bond with the complementary nt. Assume the energy of one $\mathrm{H}$-bond is close to $1 \mathrm{Kcal} / \mathrm{mol}$, then only a high mean Net- $\Delta \mathrm{G} /$ bond is expected to significantly effect the structure of mRNA over a 50-nt stretch.

miRs 'targeting 3'-UTR-Notch-1' according to the 'seedmatch axiom' are listed in TargetScan (www.targetscan.org) and MiRanda (micro.rna.org). Databases do not include miRs associated with Notch-1 function (miR-802 and its complementary star $(*)$ strand), nor hESC miRs, nor even their predicted Self- $\Delta \mathrm{G}$.

We quantified the Net- $\Delta \mathrm{G}$ of miRs folding with targets in 3'-UTR Notch-1 mRNA in >100 analyses with 30 nt-long overlapping sequences by their lowest e-values in http:// microrna.sanger.ac.uk. Each target included $10 \mathrm{nt}$ from the previous sequence. We established the eRNA baseline at a Net $-\Delta \mathrm{G}$ of $-5.00 \mathrm{Kcal}$. A value of $5.00 \mathrm{Kcal}$ is close to the average mean Net $-\Delta \mathrm{G}$ of $-4.06 \pm 1.20 \mathrm{Kcal}$ calculated by us for $37 \mathrm{miRs}$ reported to bind 3'-UTR-Notch-1 mRNA (TargetScan). Four miRs bound 3'-UTR-Notch-1 with a Net$\Delta \mathrm{G}>-10.00 \mathrm{Kcal} ; 4$ with a Net- $\Delta \mathrm{G}$ of $-6.00 \mathrm{Kcal}$ and 37 with a Net- $\Delta \mathrm{G} \leq-3.00$ Kcal. 
Table III. Anti-HHN targets in oncogenes.

\begin{tabular}{|c|c|c|c|c|c|}
\hline Name & Target & Domain & Net- $\Delta \mathrm{G}$ & Net- $\Delta \mathrm{G} /$ bond (cal) & Predicted effect \\
\hline \multirow[t]{3}{*}{ EGF-R } & $16-39$ & 5'UTR & 12.70 & $24.30 / 77=315.58$ & High \\
\hline & $79-92$ & 5'UTR & 11.60 & & \\
\hline & 282-305-signal & ORF & 7.20 & $31.50 / 290=108.62$ & Low \\
\hline \multirow[t]{3}{*}{ HER-2 } & $15-39$ & 5'UTR & 13.30 & $24.5 / 199=123.11$ & Low \\
\hline & $192-215$ & 5'UTR & 11.20 & & \\
\hline & $1088-1113$ & ORF & 9.30 & $33.8 / 999=33.86$ & None \\
\hline \multirow[t]{2}{*}{ Ras } & $73-96$ & 5'UTR & 12.40 & $12.40 / 117=105.98$ & Low \\
\hline & 2099-2122, 2123-2146 & 3'UTR & $20.20,13.70$ & $23.90 / 48=497.92$ & High \\
\hline \multirow[t]{2}{*}{ c-Myc } & $8-31,468-490$ & 5' UTR & $13.70,13.70$ & $27.40 / 483=56.76$ & None \\
\hline & $727-750,771-794$ & ORF & $11.90,13.70$ & $25.60 / 68=376.47$ & High \\
\hline \multirow[t]{2}{*}{ AUF-1 } & $61-84,169-192,248-272$ & 5'UTR & $13.30,16.50,10.10$ & $39.9 / 212=188.20$ & Medium \\
\hline & $1309-1334$ & 3'UTR & 9.10 & $\mathrm{~N} / \mathrm{A}$ & - \\
\hline \multirow[t]{2}{*}{ ELAVL } & $22-47,93-118$ & 5'UTR & $18.40,17.60$ & $36.00 / 97=371.13$ & High \\
\hline & $3049-3072,4124-4147$ & 3'UTR & $7.60,6.90$ & $14.5 / 1099=13.18$ & None \\
\hline \multirow[t]{2}{*}{ TIAL-1 } & $68-91,437-460,481-503,541-566$ & 5'UTR & $1.40,6.80,8.60,4.10$ & $20.90 / 499=41.88$ & None \\
\hline & $790-813$ & ORF & 6.90 & $\mathrm{~N} / \mathrm{A}$ & \\
\hline
\end{tabular}

CDRs: TIAL-1 (565-1743-3955), ELAVL (168-1148-6125), c-Myc (525-1889), Ras (117-962), Her-2 (4815), EGF-R (247-3879).

Table IV. Anti-HHN targets in Notch enhancer (CBH1) and Notch repressors.

\begin{tabular}{|c|c|c|c|c|c|}
\hline Name & Target position & Domain & Net- $\Delta \mathrm{G}$ & Net- $\Delta \mathrm{G} /$ bond (cal) & Predicted effects \\
\hline $\mathrm{CBH} 1$ & $\begin{array}{l}13-56,169-193 \\
262-285\end{array}$ & $\begin{array}{l}\text { 5'UTR } \\
\text { ORF }\end{array}$ & $\begin{array}{l}13.40,7.60 \\
6.50\end{array}$ & $\begin{array}{l}22.00 / 181=121.54 \\
27.50 / 274=100.36\end{array}$ & $\begin{array}{l}\text { Medium } \\
\text { Low }\end{array}$ \\
\hline RB1 & A. 92-, B.194-, B.228-, & 5'UTR, ORF & $12.70,15.30,10.40$ & $\begin{array}{l}\text { A. } 25.70 / 58=450.87 \\
\text { B. } 38.4 / 159=241.50\end{array}$ & High \\
\hline Numb-L & $\begin{array}{l}\text { A. 32-, 53-, } \\
\text { B. } 1836-, 1936\end{array}$ & $\begin{array}{l}\text { 5'UTR } \\
\text { ORF }\end{array}$ & $\begin{array}{l}9.40,12.00 \\
9.80,2.40\end{array}$ & $\begin{array}{l}21.40 / 43=497.6 \\
12.20 / 126=96.82\end{array}$ & $\begin{array}{l}\text { High } \\
\text { Low }\end{array}$ \\
\hline HES-1 & 728-,785-, 815-, & ORF & $11.00,18.70,5.70$ & A. $35.000 / 117=299.14$ & High \\
\hline TLE-1 & $\begin{array}{l}138- \\
1517-,, 1644-, 2145-\end{array}$ & $\begin{array}{l}\text { 5'UTR } \\
\text { ORF }\end{array}$ & $\begin{array}{l}8.00 \\
5.00,13.30,5.70\end{array}$ & $\begin{array}{l}\text { A. N/A } \\
24.00 / 651=36.86\end{array}$ & $\begin{array}{l}\text { None } \\
\text { None }\end{array}$ \\
\hline TP53 & A. 395-, B.715-, & ORF & $8.50,7.00$ & 41.90 & None \\
\hline
\end{tabular}

CDRs: TP53 (195-1376); TLE-1 (442-2754); RB1 (167-2953); CBH1 (167-2953).

\section{Results}

The 5'-start of Notch-1 mRNA hosts an organized GC-rich sequence. Alignments of groups of 100 nt from Notch-1, Notch-2, Numb-L, TIAL-1 and AUF-1 revealed GC-rich sequences of 20-24 nt. Searches with a sample of similar size of the 4 Notch family members confirmed the shared GCrich sequences. The 24-nt CG-rich sequence 33-56 (GGC GCT GCT GCC CGC GCT CGC CGC) is present in the 5' ORF of mRNA of Notch-1 and 5'UTR of other Notch family members.

When the 3rd nt of the sequence is removed, its GC motif is (- GC GC- GC- GC- -GC GC- - GC -GC). Each half has equal numbers of $\mathrm{G}$ and $\mathrm{C}$. The left is -GC GC- GC- GC-, while the right is -GC GC- -GC -GC. The left and right halves are asymmetrical. The 24-mer resembles a GC frame with bar code identifier, \{ G ... .T ..T ..C .. C ..T C.. C.. $\}$ or $\mathrm{G}^{1} \mathrm{~T}^{6} \mathrm{~T}^{9} \mathrm{C}^{12} \mathrm{C}^{13} \mathrm{~T}^{18} \mathrm{C}^{19} \mathrm{C}^{22}$. There are $3 \mathrm{GC}$ frames. \{-GC GC- $\},\{$ GC- GC- $\}$ and $\{-\mathrm{GC}-\mathrm{GC}\}$. We could not find identical sequences with HHN1 in other mRNAs. This sequence does not contain G-trimers, - tetramers and -pentamers. Its reverse complementary sequence, anti-HHB,

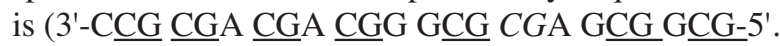

Anti-HHB folds with a higher Net- $\Delta G$ with Notch-1, Notch-2 and Notch -3 than with Notch-4 mRNA. Notch-1 mRNA does 
A.

$\Delta \mathbf{G : - 2 6 . 3 0}$

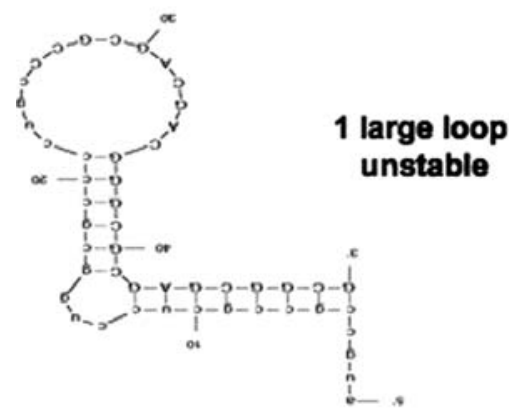

c.

$\Delta G:-29.20$
B.

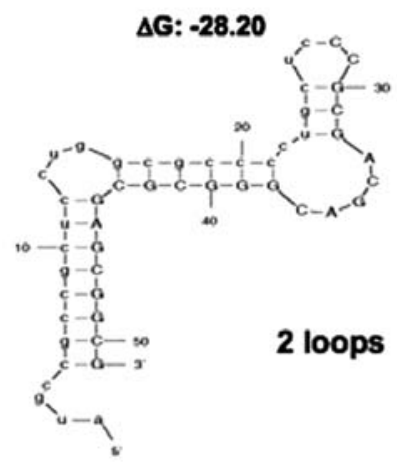

\section{2 small loops= Most stable}

Figure 1. Hybrids between anti-HHB and the Notch-1 mRNA translation start. (A) Notch-1 mRNA,1-25, (B) Notch-1 mRNA,1-27, and (C) Notch-1 mRNA,1-34. Hybrids exclude the start codon (AUG). The sequence of the target is longer than that of anti-HHB in B and C. The N1-sequence (small letters) is connected with anti-HHB (capital letters). $\Delta \mathrm{G}$ is described in Materials and methods. Figures were constructed with M-Fold.

\section{A. $\Delta$ G: $-\mathbf{2 3 . 5 0}$}
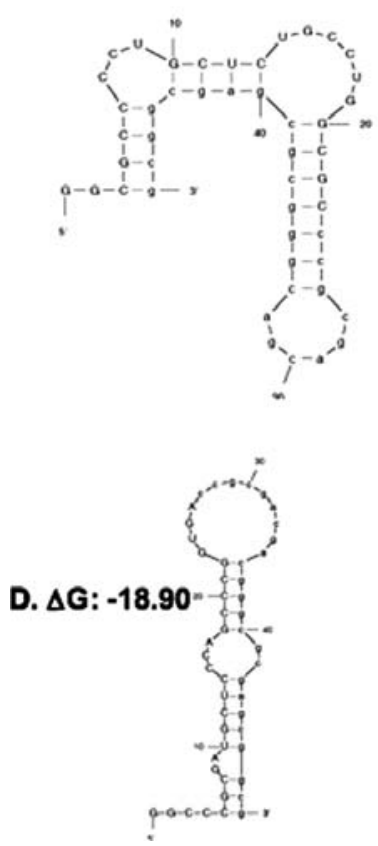

B. $\Delta$ G: -28.60 Structure I
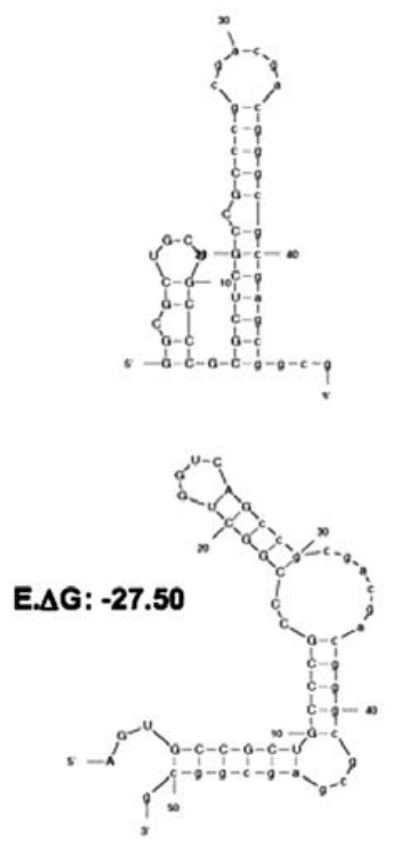

\section{C. $\Delta G:-27.90$}

Structure-11
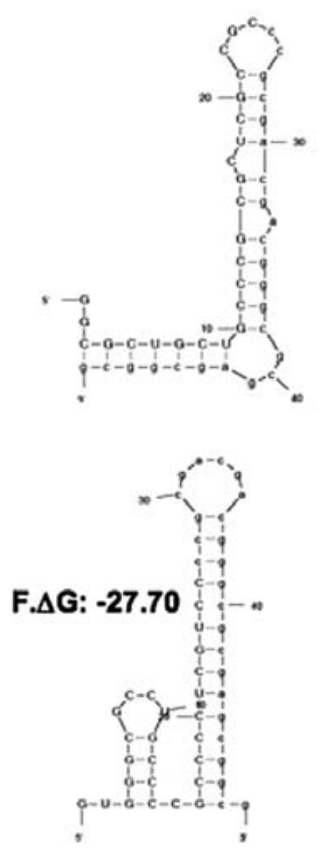

Figure 2. Folding of anti-HHB with mRNA of equal length and highest $\Delta$ Gs. Notch-1: (A) 15-37, (B) 33-56; HHBN1 - complementary to anti-HHBStructure I, (C) 33-56; HHBN1 - complementary to anti-HHB-Structure II. (D) 61-84, (E) 377-404 and (F) HER-2, 15-39.

not have 5'-UTR and has 54-nt coding for signal peptide. Anti-HHB folds with the message of the signal peptide. Notch-1(1-60) self-folds with a Self- $\Delta \mathrm{G}$ of $-18.50 \mathrm{Kcal} / \mathrm{mol}$. Anti-HHB binds to Notch-1,1-34 and 1-24 with a $\Delta \mathrm{G}$ of
$-4.06 \pm-1.20$ and-27.00 Kcal, respectively. Consequently, anti-HHB can open the self-loop between Notch-1,4-30 and Notch-1,31-60 (Fig. 1A-C). Anti-HHB has 8 targets in Notch-1,15-404 (Fig. 2A-E). Anti-HHB folds with the 

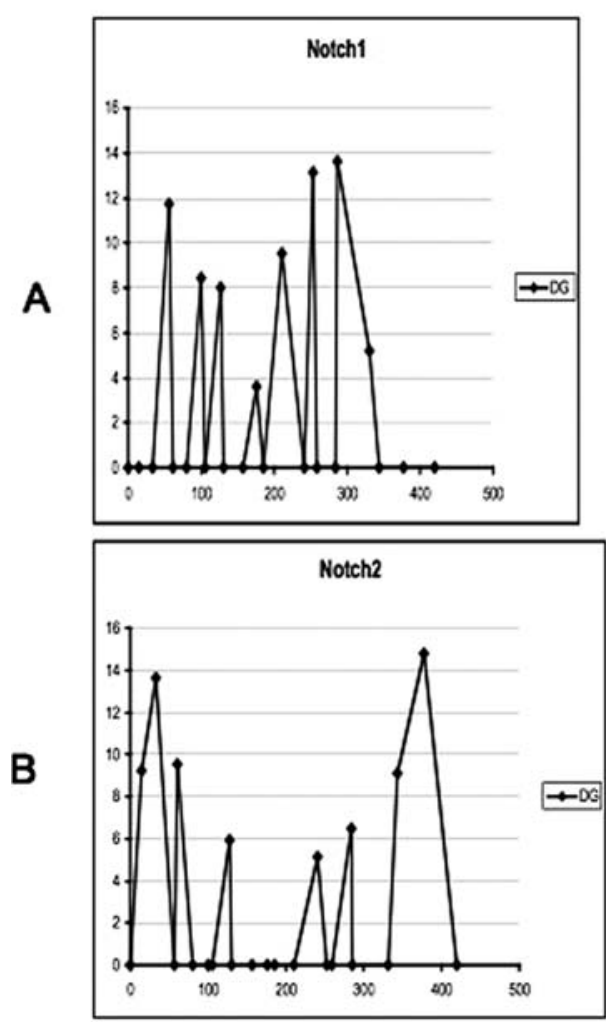
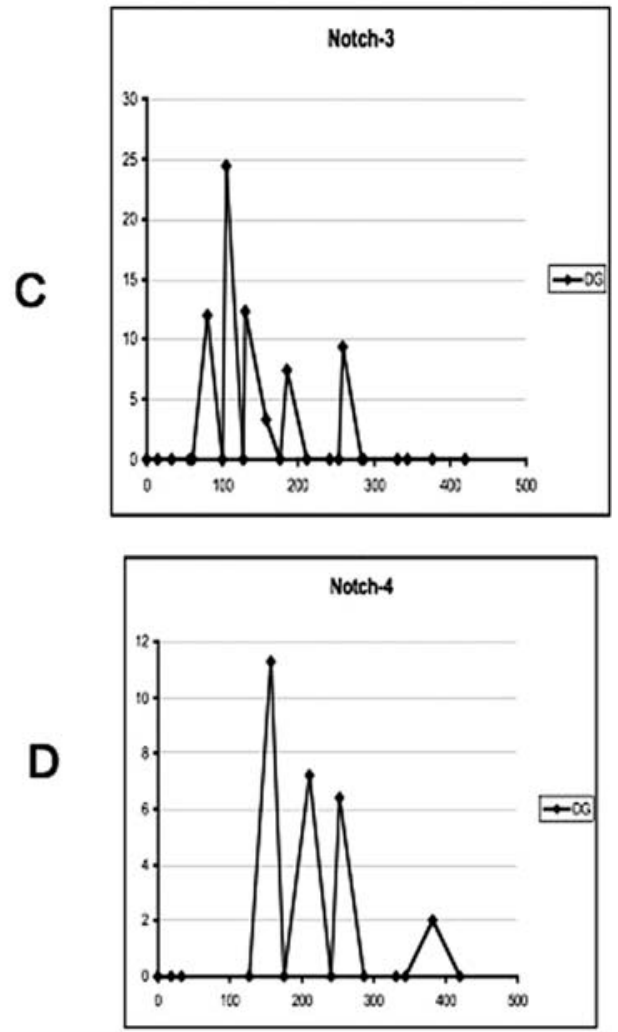

Sequence $(\mathbf{n t})$

Figure 3. Positions of the folding of anti-HHB with (A) Notch-1, (B) Notch-2, (C) Notch-3, and (4) Notch-4. Anti-HHB has more targets on Notch-1, Notch-2 and Notch-3 mRNA than on Notch-4. Each peak indicates the position of one target. The y-axis indicates the Net- $\Delta \mathrm{G}$ (- $\Delta \mathrm{G})$. Folding of anti-HHB with targets in EI4E1, EIF4A and EIF4G1. EI4E1 has a long 5'-UTR. G-tetramer and pentamer EIF4A1 has 5 dispersed G-tetramers over 1000 nt and at least 6 dispersed trimers. EIF4A1: (1-100) has 3 G tetramers, 2 G-trimers and 3 G-dimers. [1-gcaggc-gggg cc-gggg-cggc caaaccaatg cgatggcc-gg gg-c-gg-agtc-g gg-cgctctat 61 aagttgtcga ta-gg-c-ggg-ca ctccgcccta gtttctaa-gg]. The tetramers preceed the partially homologous sequence 63-82 with N1(33-56). (c) EIF4G2: (421-490) has 1 G-pentamer, 1 G-tetramer, 1 G-trimer and 2 G-dimers.[421-gagagtgcga ttgcagaa-gg ggg-tgcttct cgtttcagtg cttcttcggg cggaggagga agtaggggtg].

highest Net- $\Delta \mathrm{G}$ with N1(33-56) and N1(377-403) ( -13.50 Kcal) and a lower Net- $\Delta \mathrm{G}$ to intervening sequences. HER-2:antiHHB hybrid is shown (Fig. 2F).

The Net- $\Delta \mathrm{G}$ of anti-HHB for its targets in ORF-Notch-1 was 3.0 and 3.25 times higher than the average Net- $\Delta \mathrm{G}$ of miRs 'preferring' 3'-UTR-Notch-1. The $\Sigma$ (Net- $\Delta \mathrm{G})_{1-8}$ of $-73.8 \mathrm{Kcal}$ was 6 times higher than the Net- $\Delta \mathrm{G}$ of -11.80 and $-11.20 \mathrm{Kcal}$ of the best folding for miRs-509-3p and miR-1263 (-11.20 Kcal) to 3'-UTR. Mir-509-3p and miR-1263 targets are identified by seed-match. Targets start with nt 8335 and 8328 , respectively. These miRs cannot be used together, as they compete for the same target.

Anti-HHB targets in Notch-1 congregate in 2 regions of ORF: A (15-147) and B (241-403). Anti-HHB has a high mean Net- $\Delta \mathrm{G} /$ bond for Notch-1A and Notch-1B since it folds with non-overlapping targets with 289.39 and $217.79 \mathrm{cal} /$ bond, respectively.

Notch-2 has a 247-nt-long 5'-UTR, followed by a long message (248-331) for signal peptide. The targets of anti$\mathrm{HHB}$ are in similar positions in regions Notch-2A and Notch2B (Fig. 3A and B). Anti-HHB has a high mean Net$\Delta \mathrm{G} /$ bond on Notch-2-A (295.79 cal) and Notch-2-B (229.82 or $328.86 \mathrm{cal}) . \Sigma(\text { Net }-\Delta \mathrm{G})_{\text {Notch-1 }}$ and $\Sigma(\text { Net }-\Delta \mathrm{G})_{\text {Notch-2 }}$ are similar.
Anti-HHB has three high-affinity targets in Notch-3. $\Sigma$ $(\text { Net- } \Delta \mathrm{G})_{\text {Notch-3 }}$ is identical to $\sum$ (Net- $\left.\Delta \mathrm{G}\right)_{\text {Notch-1 }}$ and $\sum$ (Net$\Delta \mathrm{G})_{\text {Notch-2 }}$ (Fig. 3C). Anti-HHB has few targets in Notch-4 and control Gli-1 mRNA. $\sum$ (Net- $\left.\Delta \mathrm{G}\right)_{\text {Notch- } 4}$ is $35 \%$ of $\Sigma$ Net$\Delta \mathrm{G})_{\text {Notch-1/Notch-2 }}$ (Fig. 3D). Anti-HHB has a medium mean Net$\Delta \mathrm{G} /$ bond on Gli-1-A (144.44 Kcal/mol) (data not shown).

Anti-HHB, binds, in silico, to Loops I, II and IV of Notch-1(1-160) and Loops I and II of Notch-2(253-420). Net- $\Delta \mathrm{G}$ is sufficiently high to refold one loop into two smaller ones (Fig. 4A).

Changes in the position of the start codon relative to the target can affect anti-HHB effects. To inhibit translation, anti-HHB must bind to 5'-UTR, block 43S-ribosome scanning and/or translation of the elongation factors [EIF4s (-E1, -A and $-\mathrm{G})]$ (26). Shortening of 5'-UTR was proposed to increase translation efficiency, as translating-ribosome re-starts closer or directly from the start-codon. In other words, 5'UTR slicing by miRs should increase the rate of translation.

Notch-2, -3 and -4 mRNAs contain, in 5'-UTR, partially homologous sequences with Notch-1(33-56). When anti-HHB facilitates ribosome scanning by slicing 5'-UTR, it also slices ORF on the signal peptide (Loop I) and/or the following 200 nt (Loops II and III) . 
A

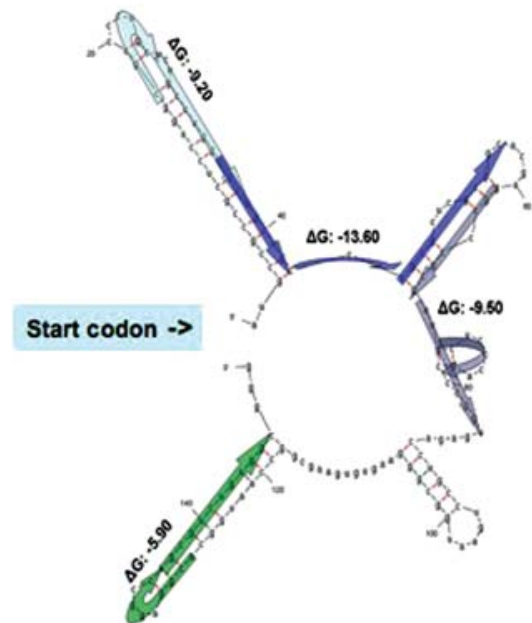

$\Sigma\{$ Net $\Delta G\}=-38.2 \mathrm{Kcal}$. Notch-1(1-160) Loops ORF start nt 1.

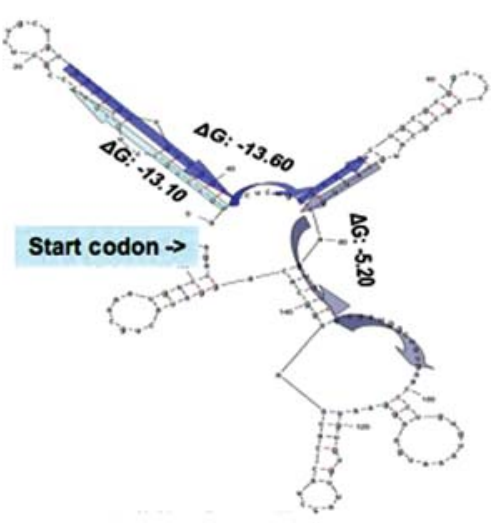

\section{$\Sigma\{$ Net $\Delta G\}=-31.9 K c$ al Notch-2( 258-428) Loops ORF start nt 258.}

B

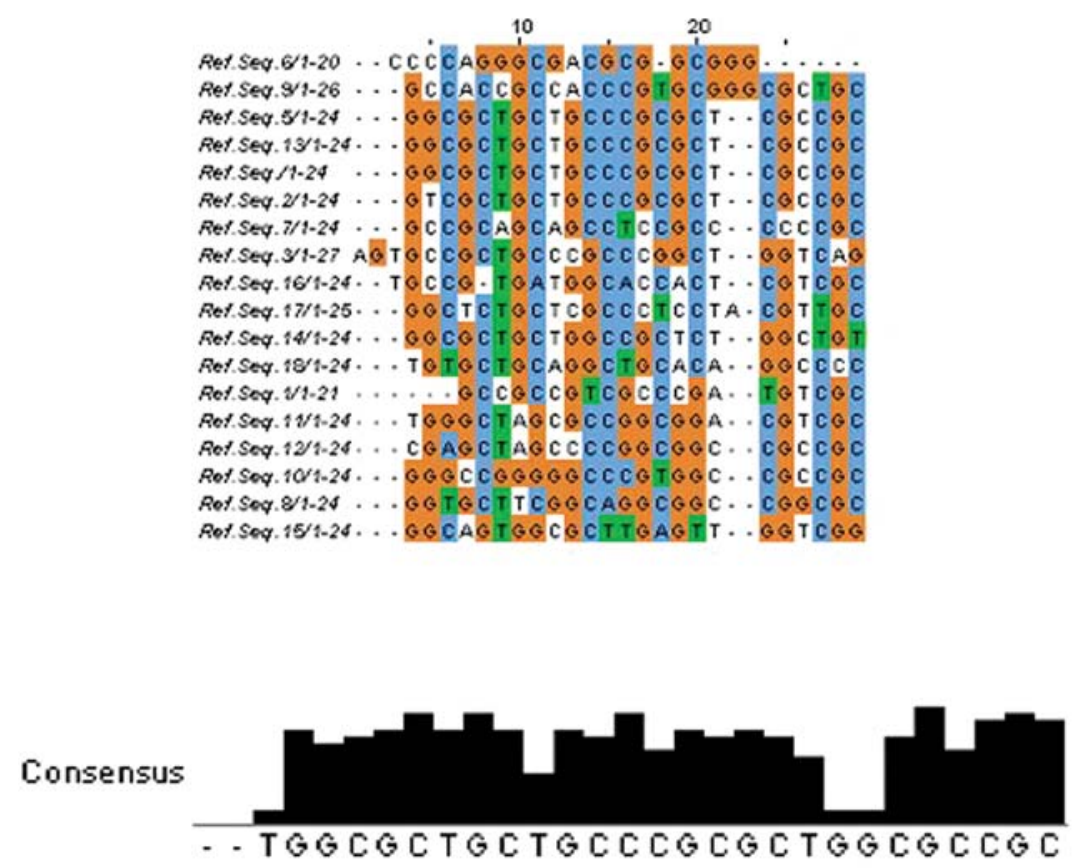

Figure 4. (A) Self-fold of Notch-1(1-160) and Notch-2(258-420). Colored arrows show where anti-HHB folds with mRNA-self-loops. Loops are clockwise from the start codon I, II, III and IV. Numbers above the arrow show Net- $\Delta$ G. In Notch-2, the anti-HHB fold sequence starts with nt- 253 , before the start codon. (B) Consensus sequence of 18 targets folded with anti-HHB with Net- $\Delta \mathrm{G}(-10.60$ and $-24.00 \mathrm{Kcal} / \mathrm{mol})$. Alignments were made with ClustallW2, and the consensus with Jalview program. All 18 sequences are listed.

To confirm the variable folding energy of anti-HHB with 5'-UTR, we used EIF4-family members as the control. The positions of the anti-HHB targets in EIF4-family members in relation to the start codon were EIF4E-1 (-117 nt), EIF4A1 $(-17 \mathrm{nt})$ and EIF4G2 (-56 nt). The Net- $\Delta \mathrm{G}$ of hybrids \{antiHHB:EIF4E-targets $\}$ was identical (EIF4A-1 and EIF4E1= $-12.50 \mathrm{Kcal}$ and $\mathrm{EIF} 4 \mathrm{G} 2=-8.5 \mathrm{Kcal}$ ) (data not shown).

mRNA of EIF4s have, in their ORF, one target for antiHHB, 3' from the start codon as follows: EIF4E-1, $450 \mathrm{nt}$; EIF4A, 300 nt and EIF4G2, 70 nt. Net- $\Delta \mathrm{G}$ of anti-HHB for $\mathrm{ORF}$ targets is $-5.00 \mathrm{Kcal}$. The low Net- $\Delta \mathrm{G}$ of miRs for targets in ORF permits ribosome to pass anti-HHB blocking (26).
According to the miR-action hypothesis, translation of EIF4 mRNA is enhanced since Net- $\Delta \mathrm{G}$ of anti-HHB for a target in 5 '-UTR is higher than for ORF. By the same logic, when Net$\Delta \mathrm{G}$ of anti-HHB for 5'-UTR is lower than for ORF, translation is inhibited. Anti-HHB has two groups of targets in c-Myc, $450 \mathrm{nt}$ of each other. The first group contains 2 sites in 5'-UTR separated by $21 \mathrm{nt}$. The Net- $\Delta \mathrm{G}$-impact is low for 5 '-UTR c-Myc targets (56,76 cal/bond), but is high (6 times) for the ORF targets $(376 \mathrm{cal} / \mathrm{mol})$. Thus, it is likely that anti-HHB can stop translation of c-Myc. The miR-action hypothesis must be verified experimentally for miR targets in 5'-UTR and ORF. 
A

Net- $\Delta G=-14.20$

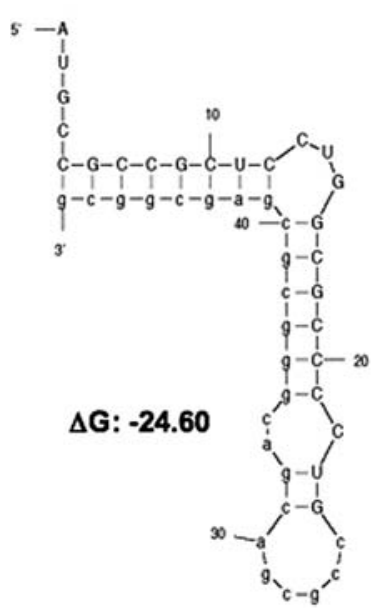

A.Anti-HHB
B

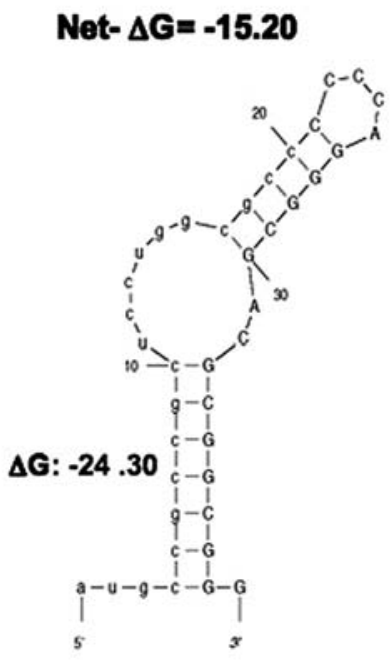

B.miR-1915
C
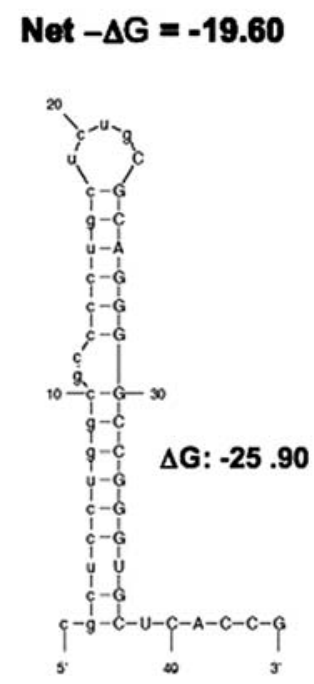

C. $\operatorname{miR}-1909$

Figure 5. Fold structure formed between hESC-miR 1909 and 1915, and the 5 ' start sequence of Notch-1 mRNA. hESC-miR1909 folds with the highest Net- $\Delta$ G. (A) Fold structure \{anti-HHB:N1,1-24\}. (B) Folded structure \{miR-1915:N1,1-20)\}. (C) Folded structure \{miR-1909:N1,8-29). The hybrid between \{miR1908:N1,4-24\}, $\Delta \mathrm{G}=-10.70$, is not shown.

Consensus target of anti-HHB. To identify a translation inhibitor, a substitute for miRs, active on multiple targets, we identified 18 targets of anti HHB with a high Net- $\Delta \mathrm{G}(-10.60$ to 24.00) (Fig. 4B). The consensus sequence contained 22 more conserved nt (TGG CGC TGC TGC CCG CGC CGC T) followed by GG and ending with a less conserved hexamer (Fig. 4B). Anti-HHB folded, in silico, with the 'consensus' with a $\Delta \mathrm{G}$ of -26.10 and a Net- $\Delta \mathrm{G}$ of $-9.70 \mathrm{Kcal}$. Therefore, from thermodynamics, anti-HHB, as eRNA, can replace at least 18 different miRs.

The consensus was similar and had 24 of 27 identical nt with Drosophila transposon IID: 31004 CG13366l CG13366 gene product from transcript CG13366-RA and a second transposon NM 137493.2, CG30116, isoform C. The sequences N1 (33-56), Gli-1 (18-41) and Ras (2099-2122) were closest to consensus. This means a similar archetype in 5'-UTR, ORF and 3'UTR. Of all of the targets of anti-HHB, Notch-1(1-20) was the closest to the common ancestor (data not shown).

Anti-HHB targets mRNA of Notch-1 function-associated proteins. Anti-HHB had a high mean Net- $\Delta \mathrm{G} /$ bond on Notch-1, HIF-1 $\alpha$, Slug, RB1, EGF-R, c-Myc, Ras (3'-UTR) ELAVL/HuR and Numb-L (Tables II-IV). Anti-HHB folded, in silico, to two targets in 5'-UTR of EGF-R and HER-2. Its targets in Ras are in 3'-UTR.

Net- $\Delta \mathrm{G}$ of the folding of anti-HHB to SCFs decreased in the order Slug $>$ Nanog $>$ Sox $-2>$ Oct $3,4>$ Snail $>$ Twist $>$ Ronin . Therefore, anti-HHB may inhibit expression of Notch-1, Notch-2, Notch-3, EGF-R, HER-2, Slug, Nanog, Ras and c-myc.

Anti-HHB folded with Notch-1 antagonists RB1, HES-1, and Numb-L (data not shown) with a high Net- $\Delta \mathrm{G} /$ bond and with antagonists, TLE-1 and p53 with low Net- $\Delta \mathrm{G} /$ bond.
Therefore, anti-HHB may inhibit one set of Notch-1 suppressors (RB1 and HES-1) but does not affect the others (p53, TLE-1) (29,30). Experimental studies are needed to determine the effects of anti-HHN in relation to changes in the amount of these proteins.

Anti-HHB folds with a higher Net- $\Delta \mathrm{G}$ with c-Myc enhancer, AUF-1, than with c-Myc suppressors, ELAVL (Hur-1) (31-34) and TIAL-1/TIAIR-1 (31-34). AUF-1 and TIAR control c-Myc-dependent proliferation. Anti-HHB can increase the ratios ELAVL (HUR-1) to AUF-1 and TIAL-1/ TIAIR-1 to AUF-1. Overall, since anti-HHB represses c-Myc protein synthesis, directly and indirectly, it is a candidate to repress EMT.

Anti-HHB has 3 targets in 5'-UTR of HIF-1 $\alpha$ and its associate, Slug. Targets in HIF- $1 \alpha$ and Slug are concentrated in 238 and $114 \mathrm{nt}$, respectively. Consequently, anti-HHB has a high Net- $\Delta$ G/bond on HIF- $1 \alpha$ and Slug. Anti-HHB appears selective as its targets on other SCFs associated with HIF-1 $\alpha$, Snail and Twist, are distant from each other; thus anti-HHB has a low Net- $\Delta \mathrm{G} /$ bond, $<-100 \mathrm{cal}$.

miR*-1915-complementary (star) strand is partially homologous with Notch-1,33-56. miR-1915,47-66 folds with HHBN1. The pre-miR-1915R* star strand (6-33) has 12 identical nt with HHBN1. miR-1915 folds with all targets of anti-HHB in Notch-1 with a similar and higher Net- $\Delta \mathrm{G}$ (Fig. 5A-C). The complementary strand of miR-1915 has 11 identical nt with HHBN1. This number of 'matches' is similar with that required for 'seed-match' recognition by miR.

Additional hESC-miRs fold, in silico, with Notch-1,4-30. miR-1909 folds with Notch-1,8-29 (Net- $\Delta \mathrm{G}=-19.60 \mathrm{Kcal}$ ). Net- $\Delta \mathrm{G}$ miR-1909 is $50 \%$ higher than the Net- $\Delta \mathrm{G}$ of antiHHB. miR-1908 folds with Notch-1(4-24) with a Net- $\Delta \mathrm{G}$ of $-10.80 \mathrm{Kcal}$. Therefore, selection of candidate eRNAs based 
on thermodynamic and RNA structure rules can create miRmimicks capable of inhibiting translation of many proteins and identifying the 'missing miRs' responsible for repressing cancer stem cell division.

\section{Discussion}

We identified a uniquely organized GC-rich sequence in Notch-1 mRNA,33-56. The sequence contained two asymmetrical GC-rich dodecamers and a bar code by another 8 nt. Its reverse complementary sequence (anti-HHB) folded with high Net- $\Delta \mathrm{G}$ with Notch-1,33-56. Anti-HHB has several targets in the ORF of Notch-1 mRNA, thus its inhibition of Notch translation should be stronger than by natural miR 802 (36) and 509-3p. Only these two natural miRs fold with a similar Net- $\Delta \mathrm{G}$ with targets in 3 '-UTR of Notch-1 mRNA. Such selected eRNA may solve the need for pluripotent anticancer effectors.

To identify anti-HHB, we introduced a novel in silico approach for the quantification of $\Delta \mathrm{G}$, Net- $\Delta \mathrm{G}$ and $\Sigma$ [Net- $\Delta \mathrm{G} /$ bond]. We verified that $\Delta \mathrm{G}$ is higher than Self- $\Delta \mathrm{G}$ of the stem loop. The 'seed-match' approach and predictions of total $\Delta \mathrm{G}$ treat targets as short sequences removed from the natural context of mRNA. The emphasis on targets located in their predominant majority in 3'-UTR obeys the axiom that mRNA circularizes 5'-3' and is stored, until use. What occurs when cancer cells divide several times in 2-4 days and most RNA has no time to be stored in its daughter cells?

To predict the specific energy of folding, we introduced the Net- $\Delta \mathrm{G}$ value: i) the Self- $\Delta \mathrm{G}$ of each unfolded RNA partner and ii) the energetic impact of folding on longer sequences than one, 20- to 24-nt-long target.

Our in silico findings showed that anti-HHB can mediate a 4-throng approach to inhibit EMT by inhibiting simultaneously the translation of Notch-1, c-Myc, HIF-1 $\alpha$ and Slug. Its effects may be potentiated by its low affinity for Notch suppressors. Such 'selective weakness' is important to inhibit Notch-1 translation more than natural miRs or human-made siRNA.

The similarity of the targets of anti-HHB with the targets of newly identified hESC-miR 1908, 1909 and 1915 and not of miR-302b members (data not shown) in Notch-1 mRNA,1-403 was unexpected.

hESC-miR-1900 expression is activated by Sox-2 and Nanog. Their expression declined when cells differentiated and the levels of Sox-2 and Nanog declined. We were tempted to propose that miR-1900 binds multiple sites and blocks Notch-1 mRNA translation. Thus, anti-HHB may be an ancestor of natural miRs, or a general RNA inhibitor of bacterial genes diversified in evolution.

Some miRs originate from intron-exon boundaries, which include parts of coding RNAs or perhaps 'domesticated transposons.'

The closest natural homologs of anti-HHB are miR-1909 and 1915. Both have coding sequences. The sequence of miR-1909 is MVSAGACPGAVPAQGPGAHRX. This sequence is highly homologous with Full=Period circadian

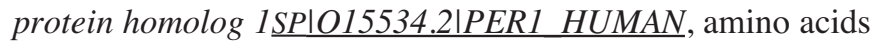
21-34. The miR-1915 sequence, starting with the miR* strand, is E-AAP-CLAA-R-AV-HPWAPGRRGGGGPS. The
miR-802 sequence also appears to be translatable and resembles a Zn-finger. Why some miRs have translatable sequences is unknown.

Requirements for the prediction of candidate targets of created eRNAs. The increased complexity of cancer survival pathways require development of more sensitive and automated software to perform calculations and to expand the prediction of effects of anti-HHB on additional targets listed by the human genome. For inhibition of cancer, targets must be searched for in the whole mRNA and no longer only in 3'-UTR. Targets cannot be defined experimentally without exogenous mRNA probes; novel parameters to Net- $\Delta \mathrm{G}$ and $\Sigma[$ Net- $\Delta \mathrm{G} /$ bond $]$ are needed to predict the effectiveness of eRNAs (and of miRs alike). Anti-HHB can bind to promoters. Anti-HHB folded with the Notch-1 promoter sequence bound by p53 $(27,28)$ which suggests that it can interfere with transcription (data not shown).

Implication of the prediction of Net- $\Delta G$ and Net- $\Delta G /$ bond in the creation of eRNAs. The phyllogram of anti-HHB targets show that these targets were ignored by natural miR selection, in the case that there were any. High Net- $\Delta \mathrm{G} /$ bond should decrease the effective RNA concentrations at sub-toxic levels for healthy tissue compared with miR. The presence of $3 \mathrm{GC}$ motifs in HHN1 allows the creation of artificial RNA-mimics with a defined frame and modified bar code. The sequence of anti-HHB allows its loading on Argonaute-2 proteins; it can be extended to increase loading efficiency.

Anti-HHB can create novel T-cell immunogenic peptides in cancer. Inhibition of the translation of mRNA in ORF should be followed by degradation of partially translated protein. Canonical miRs do not act on ORF. When Notch-1 mRNA translation stops at nt 400, the peptide Notch-1,1-133 is degraded. Notch-1,1-133 contains several 9- to 10-amino acid-long peptides, which can bind with high affinity to HLA-A2. A part of the Notch-1 peptide (1-133) is already in the endoplasmic reticulum and continues to the proteasome. From there, short peptides are loaded to HLA-A, B- and C and are presented as novel Notch-1 cancer antigens to $T$ cells which activate surveillance in patients with tumors resistant to chemotherapy. Degradation of complete Notch-1 protein follows different rules. Peptides from N1ICD bind more strongly to HLA-A2 and are presented to T cells.

\section{Acknowledgements}

This study was supported by a Licensing agreement by Apthera Corporation - MDACC, The Graduate School for Biomedical Sciences (Y.L.), the Estia-Net Program (European Union) and a 21st Century Grant from the Government of Japan (T.M.).

\section{References}

1. Bartel DP: MicroRNAs: target recognition and regulatory functions. Cell 136: 215-233, 2009.

2. Kota J, Chivukula RR, O'Donnell KA, et al: Therapeutic microRNA delivery suppresses tumorigenesis in a murine liver cancer model. Cell 137: 1005-1017, 2009. 
3. Tay Y, Zhang J, Thomson, et al: MicroRNAs to Nanog, Oct4 and Sox 2 coding regions modulate embryonic stem cell differentiation. Nature 455: 123-129, 2008.

4. Henke JI, Goergen HD, Zheng J, et al: microRNA-122 stimulates translation of hepatitis C virus RNA. EMBO J 27: 3300-3310, 2008.

5. Ørom UA, Nielsen FC and Lund AH: MicroRNA-10a binds the 5 '-UTR of ribosomal protein mRNAs and enhances their translation. Mol Cell 30: 460-471, 2008.

6. Besse $\mathrm{F}$ and Ephrussi A: Translational control of localized mRNAs: restricting protein synthesis in space and time. Nat Rev Mol Cell Biol 9: 971-980, 2008.

7. Tsuda N, Ishiyama S, Li Y, et al: Synthetic microRNA designed to target glioma-associated antigen 1 transcription factor inhibits division and induces late apoptosis in pancreatic tumor cells. Clin Cancer Res 12: 6557-6564, 2006.

8. Tsuda N, Kawano K, Efferson CL and Ioannides CG: Synthetic microRNA and double-stranded RNA targeting the 3'untranslated region of HER-2/neu mRNA inhibit HER-2 protein expression in ovarian cancer cells. Int J Oncol 27: 1299-1306, 2005.

9. Mine T, Matsueda S, Li Y, et al: Breast cancer cells expressing stem cell markers CD44 ${ }^{+}$CD24 lo are eliminated by Numb-1 peptide-activated $\mathrm{T}$ cells. Cancer Immunol Immunother 58: 1185-1194, 2009.

10. Mine T, Ferrone S, Vlastos G, et al: Working hypothesis: elimination of cancer stem-cells in solid tumors by immunogene therapy using cancer vaccines and designed duplex-micro RNA. Current Cancer Ther Rev 9: 217-226, 2009.

11. Mine T, Matsueda S, Gao H, et al: The density of Jagged-1 (Jag-1) on the neighboring cell decides phenotype specification of progenitors of Taxol-resistant (TX Res) ovarian cells. Oncol Rep 23: 1537-1543, 2010.

12. Hurlbut GD, Kankel MW, Lake RJ, and Artavanis-Tsakonas S Crossing paths with Notch in the hyper-network. Curr Opin Cell Biol 19: 166-175, 2007

13. Sahlgren C, Gustafsson MV, Jin S, Poellinger L, et al: Notch signaling mediates hypoxia-induced tumor cell migration and invasion. Proc Natl Acad Sci USA 105: 6392-6407, 2008.

14. Bedogni B, Warneke JA, Nickoloff BJ, et al: Notch1 is an effector of Akt and hypoxia in melanoma development. J Clin Invest 118: 3660-3670, 2008.

15. Klinakis A, Szabolcs M and Politi K: Myc is a Notch1 transcriptional target and a requisite for Notch1-induced mammary tumorigenesis in mice. Proc Natl Acad Sci USA 103: 9262-9266, 2006.

16. Hurlbut GD, Kankel MW and Artavanis-Tsakonas S: Nodal points and complexity of Notch-Ras signal integration. Proc Natl Acad Sci USA 106: 2218-2223, 2009

17. Niessen K, Fu Y, Chang L, et al: Slug is a direct Notch target required for initiation of cardiac cushion cellularization. J Cell Biol 182: 315-325, 2008.

18. Leong KG, Niessen K, Kulic I, et al: Jagged1-mediated Notch activation induces epithelial-to-mesenchymal transition through Slug-induced repression of E-cadherin. J Exp Med 204: 2935-2948, 2007.

19. Bar M, Wyman SK and Fritz BR: MicroRNA discovery and profiling in human embryonic stem cells by deep sequencing of small RNA libraries. Stem Cells 26: 2496-2505, 2008.
20. Krüger J and Rehmsmeier M: RNA hybrid: microRNA target prediction easy, fast and flexible. Nucleic Acids Res 34: W451-W454, 2006.

21. Reeder J, Steffen P and Giegerich R: pknots RG: RNA pseudoknot folding including near-optimal structures and sliding windows. Nucleic Acids Res 35: W320-W324, 2007.

22. Mathews DH, Sabina JM, Zuker M and Turner DH: Expanded sequence dependence of thermodynamic parameters improves prediction of RNA secondary structure. J Mol Biol 288: 911-940, 1999.

23. Zuker M: M-fold web server for nucleic acid folding and hybridization prediction. Nucleic Acids Res 31: 3406-3415, 2003.

24. Rice P, Longden I and Bleasby A: EMBOSS: The European Molecular Biology Open Software Suite Trends in Genetics 16: 276-277, 2000.

25. Webster RJ, Giles KM, Price KJ, et al: Regulation of epidermal growth factor receptor signaling in human cancer cells by microRNA-7. J Biol Chem 9: 5731-5741, 2009.

26. Gu S, Jin L, Zhang F, et al: Biological basis for restriction of microRNA targets to the 3'-UTR region in mammalian mRNAs. Nat Struct Mol Biol 16: 144-150, 2009.

27. Lefort K, Mandinova A, Ostano P, et al: Notch1 is a p53 target gene involved in human keratinocyte tumor suppression through negative regulation of ROCK $1 / 2$ and MRCK-kinases. Genes Dev 21: 562-577, 2007.

28. Yugawa T, Handa K, Narisawa-Saito M, et al: Regulation of Notch1 gene expression by p53 in epithelial cells. Mol Cell Biol 27: 3732-3742, 2007.

29. Dominguez M: Interplay between Notch signaling and epigenetic silencers in cancer. Cancer Res 66: 8931-8934, 2006.

30. Fraga MF, Berdasco M, Ballestar E, et al: Epigenetic inactivation of the groucho homologue gene TLE1 in hematologic malignancies. Cancer Res 68: 4116-4119, 2008.

31. Brewer G: An A+U-rich element RNA-binding factor regulates c-myc mRNA stability in vitro. Mol Cell Biol 11: 2460-2466, 1991.

32. Liao B, Hu Y and Brewer G: Competitive binding of AUF1 and TIAR to MYC mRNA controls its translation. Nat Struct Mol Biol 14: 511-518, 2007.

33. Kim HH, Kuwano Y, Srikantan S, et al: HuR recruits let-7/ RISC to repress c-Myc expression. Genes Dev: 23: 1743-1748, 2009.

34. Topisirovic I, Siddiqui N, Orolicki S, et al: Stability of eukaryotic translation initiation factor $4 \mathrm{E}$ mRNA is regulated by HuR, and this activity is dysregulated in cancer. Mol Cell Biol 29: 1152-1162, 2009.

35. Ishiyama S, Matsueda M, Jones LA, et al: Novel natural immunogenic peptides from Numb1 and Notch1 proteins for $\mathrm{CD}^{+}$cells in ovarian ascites. Int J Oncol 30: 889-898, 2007.

36. Kuhn DE, Nuovo GJ, Martin MM, et al: Human chromosome 21-derived miRNAs are overexpressed in Down syndrome brains and hearts. Biochem Biophys Res Commun 370: 473-477, 2008. 